\title{
Calagem e adubação NPKS: (I) Efeito no crescimento de mudas de grápia cultivadas em horizontes A e B de um Argissolo Vermelho distrófico arênico
}

\author{
Liming and NPKS fertilization (I): Effect on growth of seedlings of grápia grown in \\ horizons A and B of a Rhodic Paleudalf soil
}

\author{
Fernando Teixeira Nicoloso ${ }^{\mathrm{I}}$ Roni Paulo Fortunato ${ }^{\mathrm{II}}$ Marco Aurélio de Freitas Fogaça ${ }^{\mathrm{III}}$ \\ Flávio Zanchetti ${ }^{\mathrm{IV}}$
}

\section{RESUMO}

A grápia (Apuleia leiocarpa (Vog.) Macbride) é uma espécie florestal brasileira de grande interesse madeireiro, encontrando-se, atualmente, em processo de extinção. $O$ presente trabalho objetivou avaliar os efeitos da interação entre níveis de $\mathrm{pH}$ do solo e da adubação NPKS no crescimento de mudas de grápia. Foram avaliados 12 tratamentos em esquema trifatorial completo $(3 \times 2 \times 2)$, em que os fatores consistiram da combinação de três níveis de $p H(4,8,5,5$ e 6,0), dois níveis de adubação (sem e com adubação NPKS 40:40:40:30 $\mathrm{mg} \mathrm{kg}^{-1}$, respectivamente) $e$ dois horizontes (A e B) de um Argissolo Vermelho distrófico arênico. Como parcela experimental, foram usados vasos $(3,5 \mathrm{~kg})$, em delineamento experimental inteiramente casualizado com cinco repetições por tratamento. A análise do crescimento das plantas foi realizada mensalmente por meio da altura de planta, do diâmetro do caule e do número de folhas. Aos 150 dias após a emergência das plantas, avaliaram-se, ainda, a matéria seca de raízes, da parte aérea e do total da planta, o comprimento das raízes e a relação entre a matéria seca de raízes e da parte aérea. Houve diminuição do crescimento das plantas pela calagem do solo (horizonte A), sugerindo a adaptação da espécie às condições de solo ácido. A adubação NPKS resultou em aumento de crescimento das plantas somente em condição de solo ácido $(\mathrm{pH} 4,8)$.

Palavras-chave: acidez do solo, $\mathrm{pH}$ do solo, alumínio, Apuleia leiocarpa.

\section{ABSTRACT}

Grápia (Apuleia leiocarpa (Vog.) Macbride) is a Brazilian forest species with great interest for timber-trade. Additionally, due to deforestation, it bas been considered in extinction process. The present research aimed to evaluate the

\begin{abstract}
interaction between levels of soil $p H$ and NPKS fertilization on growth of seedlings of grápia. Twelve treatments were used in a complete trifactorial scheme $(3 \times 2 \times 2)$, represented by the combination of three levels of soil $\mathrm{pH}$ (4.8, 5.5 and 6.0), two levels of fertilization (addition or not of NPKS - 40:40:40:30mg $\mathrm{kg}^{-1}$, respectively) and two horizons (A and B) of a Rhodic Paleudalf soil. Each pot of $3.5 \mathrm{~kg}$ of capacity were arranged in a completely randomized design with five replicates per treatment. Plant height, stem collar diameter and leaves number was monthly evaluated. 150 days after plant emergence, above and belowground dry matter, total root length, and root to shoot dry matter ratio were also evaluated. Liming reduced growth of plants grown in soil of horizon A (topsoil), which suggests that grápia is well adapted to acid conditions. NPKS application increased plant growth only under acid soil ( $\mathrm{pH}$ 4.8).
\end{abstract}

Key words: soil acidity, soil pH, aluminum, Apuleia leiocarpa.

\section{INTRODUÇÃO}

A grápia (Apuleia leiocarpa (Vog.) Macbride) é uma espécie arbórea nativa com ampla, mas descontínua distribuição geográfica no território brasileiro, devido principalmente ao desmatamento e à falta de reposição por meio do reflorestamento (MATTOS \& GUARANHA, 1983). O interesse pela espécie advém de suas qualidades, pois sua madeira é própria para construções civis e navais (REITZ et al., 1988).

\footnotetext{
'Departamento de Biologia, Universidade Federal de Santa Maria (UFSM), Campus Universitário, Camobi, 97105-900, Santa Maria, RS, Brasil. E-mail: ftnicoloso@yahoo.com. Autor para correspondência.

IISLC Agrícola Ltda, Luziânia, GO, Brasil.

IIIPrograma de Pós-graduação em Agronomia. UFSM, Santa Maria, RS, Brasil.

${ }^{\mathrm{IV}}$ Prefeitura Municipal de Seara, Seara, SC, Brasil.
} 
No Estado do Rio Grande do Sul, a espécie apresenta vasta e expressiva dispersão por toda a floresta latiofoliada da bacia do Alto Uruguai e bacia do Rio Jacuí (REITZ et al., 1988). Os solos predominantes nessas áreas são os Latossolos e os Neossolos, os quais possuem distintas características químicas, a exemplo do teor de fósforo disponível, $\mathrm{pH}$ e da saturação por bases e por Al (BRASIL, 1973). Portanto, aparentemente, a grápia apresenta grande capacidade de adaptação à fertilidade e acidez do solo.

A inibição do crescimento vegetal pela acidez do solo resulta de interações de fatores químicos específicos. Para MARSCHNER (1991), nos solos minerais ácidos, os principais impedimentos ao crescimento vegetal são: (i) aumento nas concentrações de $\mathrm{H}^{+}, \mathrm{Al}^{+3}$ e $\mathrm{Mn}^{2+}$, (ii) decréscimo na concentração dos macronutrientes catiônicos $\left(\mathrm{Mg}^{2+}, \mathrm{Ca}^{2+}\right.$ e $\left.\mathrm{K}^{+}\right)$, e (iii) decréscimo na solubilidade de fósforo e molibdênio, resultando em inibição do crescimento de raízes e da absorção de água.

Embora existam grandes variações quanto ao grau de sensibilidade às limitações químicas dos solos, uma vez que as espécies florestais nativas reagem de forma diferenciada à correção da acidez e ao aumento na disponibilidade de nutrientes, a ocorrência de solos ácidos e/ou com baixos níveis de fertilidade são entraves que têm prejudicado a aquisição de nutrientes e dificultado o estabelecimento das mudas em condições de campo (FURTINI NETO et al., 1999b).

Resposta positiva à calagem foi observada por FURTINI NETO et al. (1999b) em cássia verrugosa (Senna multijuga) e ipê mirim (Stenolobium stans). HUANG \& BACHELARD (1993) verificaram crescimento adequado de Eucalyptus mannifera em solo ácido, enquanto o crescimento de Pinus radiata nessa condição foi deficiente. Já NICOLOSO et al. (1999), salientam que a presença de $53 \%$ de saturação de $\mathrm{Al}^{3+}$ e a baixa concentração de $\mathrm{P}$ no horizonte $\mathrm{B}$ de um Argissolo Vermelho distrófico arênico foram responsáveis pelo menor crescimento de mudas de grápia em relação ao cultivo em solo do horizonte A. Utilizando a técnica de minirizotrons, FORTUNATO \& NICOLOSO (2004) constataram que a tolerância de plântulas de grápia ao $\mathrm{Al}^{3+}\left(10 \mathrm{mg} \mathrm{L}^{-1}\right)$ dependeu da elevação do $\mathrm{pH}$ da rizosfera.

Em um Argissolo Vermelho distrófico arênico, sob condições de pH natural $(4,6$ a 4,8) em experimentos em casa de vegetação, NICOLOSO et al. (1999, 2001) e MISSIO et al. (2004) observaram que mudas de grápia responderam significativamente à adubação NPKS.

Considerando todos os relatos existentes na literatura para a grápia, não existem estudos em relação à possível interação entre os efeitos do pH do solo e da adubação NPKS no crescimento dessa espécie. Além disso, a grápia possui sistema radicular acentuadamente pivotante e com poucas raízes secundárias no início de seu desenvolvimento vegetativo (NICOLOSO et al., 2000), fato que justifica o interesse de se estudar o efeito de diferentes horizontes de um mesmo solo no crescimento dessa espécie. Portanto, utilizando-se dois horizontes de um Argissolo Vermelho distrófico arênico, possuindo diferentes saturações de $\mathrm{Al}^{3+}$, o presente trabalho objetivou avaliar os efeitos da calagem e da adubação NPKS no crescimento de plantas jovens de grápia.

\section{MATERIAL E MÉTODOS}

O trabalho foi conduzido no período de 28 de agosto de 1998 a 25 de janeiro de 1999, em casa de vegetação, do Departamento de Fitotecnia do Centro de Ciências Rurais da Universidade Federal de Santa Maria, RS.

Foram avaliados 12 tratamentos em esquema trifatorial completo $(3 \times 2 \times 2)$, em que os fatores consistiram da combinação de três níveis de $\mathrm{pH}(4,8$, 5,5 e 6,0), dois níveis de adubação (sem e com adubação NPKS, respectivamente 40:40:40:30mg kg-1, correspondendo à metade da recomendação sugerida por NICOLOSO et al., 2001) e dois horizontes (A e B) de um Argissolo Vermelho distrófico arênico. O delineamento experimental usado foi de tratamentos inteiramente casualizados, com cinco repetições. A unidade experimental constituiu-se de um vaso com 3,5kg de solo e duas plantas, que foram submetidos a rodízio periódico para evitar algum efeito de localização na casa de vegetação.

O solo foi coletado na camada de 0 a $65 \mathrm{~cm}$ de profundidade do horizonte A e de 130 a $165 \mathrm{~cm}$ do horizonte B. Como resultados das análises químicas do solo (conforme metodologia descrita por TEDESCO et al., 1995), obteve-se para o horizonte A: $\mathrm{pH} 4,8 \mathrm{em}$ água (1:1); M.O. 0,7\%; saturação por bases 25\%; saturação por $\mathrm{Al}^{3+} 43 \%$; $\mathrm{P} 8,0 \mathrm{mg} \mathrm{L}^{-1}$; K 60,0mg L-1 ; Ca

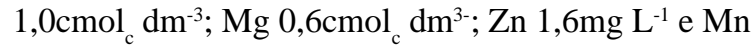
$10,6 \mathrm{mg} \mathrm{L}^{-1}$. Para o horizonte B obteve-se: $\mathrm{pH}$ 4,7 em água (1:1); M.O. 0,1\%; saturação por bases $19 \%$;

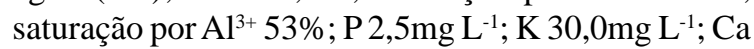

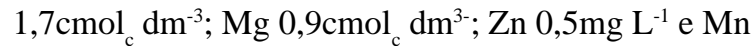
$5,1 \mathrm{mg} \mathrm{L}^{-1}$.

Após a realização da análise do solo, efetuou-se a correção da acidez (dados não apresentados), de acordo com índice SMP (para pH em água atingir o nível desejado) com uso de $\mathrm{CaCO}_{3} \mathrm{e}$ $\mathrm{MgCO}_{3}$, mantendo a relação Ca:Mg em nível 2:1, com 
base em uma curva de pré-incubação do solo por um período de 45 dias. Esse tempo foi determinado experimentalmente como sendo aquele necessário para atingir os valores de referência dos tratamentos de níveis de $\mathrm{pH}$. Nessas condições, o solo foi incubado com umidade a $60 \%$ da capacidade de campo.

Foram utilizadas sementes de plantas adultas de grápia (Apuleia leiocarpa (Vog.) Macbride) coletadas em junho de 1998, no município de Dona Francisca, RS. Antes da semeadura, os tratamentos contendo adubação receberam os nutrientes na forma de solução nutritiva a $40 \mathrm{mg} \mathrm{kg}^{-1} \mathrm{de} \mathrm{N}\left(\mathrm{KNO}_{3}\right.$ e $\left.\mathrm{NH}_{4} \mathrm{NO}_{3}\right)$, $40 \mathrm{mg} \mathrm{kg}^{-1}$ de $\mathrm{P}\left(\mathrm{NaH}_{2} \mathrm{PO}_{4}\right)$, 40mg kg-1 de $\mathrm{K}\left(\mathrm{KNO}_{3}\right)$ e $30 \mathrm{mg} \mathrm{kg}^{-1}$ de $\mathrm{S}\left(\mathrm{Na}_{2} \mathrm{SO}_{4}\right)$. A razão entre $\mathrm{N}-\mathrm{NO}_{3}^{-}: \mathrm{N}_{-} \mathrm{NH}_{4}^{+}$ da adubação foi mantida em 2:1.

A semeadura foi realizada com a colocação de seis sementes em cada vaso, após sofrerem a superação da dormência com ácido sulfúrico concentrado por 20min. Aos 10 dias após a germinação, procedeu-se o desbaste deixando-se as duas plantas mais uniformes. A umidade do solo foi mantida entre 50 e $60 \%$ da capacidade de campo, por meio de irrigação com água deionizada sempre por meio de aferições diárias por pesagem.

A análise do crescimento foi realizada aos 30, 60, 90, 120 e 150 dias após a emergência (DAE) das plantas, por meio do monitoramento da altura da planta, do diâmetro do caule (a $0,5 \mathrm{~cm}$ do nível do solo) e do número de folhas remanescentes. Aos 150 DAE, avaliou-se, ainda, a matéria seca de raízes, da parte aérea e do total da planta, o comprimento das raízes, conforme metodologia descrita por TENNANT (1975), e a relação entre a matéria seca das raízes e da parte aérea.

Foi realizada a análise de variância para todas as variáveis, considerando o esquema trifatorial para cada época analisada, sendo que, como não houve interação tripla, para as interações duplas significativas, em nível de 5\% de probabilidade de erro, procedeu-se a avaliação por meio da análise de regressão polinomial para o fator quantitativo $(\mathrm{pH}$ do solo) e pelo teste de Duncan para os fatores qualitativos (adubação e horizonte do solo).

\section{RESULTADOS E DISCUSSÃO}

Para altura da planta, diâmetro de caule, número de folhas e matéria seca da planta, houve efeito do $\mathrm{pH}$ versus horizonte do solo. A altura (Figura 1a) e o diâmetro de caule (Figura 1b) das plantas cultivadas no horizonte A do solo, a partir dos 90 dias após a emergência (DAE), decresceram linearmente pela elevação do $\mathrm{pH}$ do solo. Semelhantemente, porém somente aos 150DAE observou-se o maior número de folhas por planta na ausência de calagem (Figura 1c). As matérias secas de raízes e da parte aérea da plantas, analisadas apenas aos 150DAE, também decresceram linearmente pela elevação do $\mathrm{pH}$ do horizonte A do solo (Figura 1d). Verificou-se que o declínio da matéria seca da parte aérea foi mais acentuado que aquele observado nas raízes, indicando que a elevação do $\mathrm{pH}$ afetou mais o crescimento da parte aérea, tanto que a elevação do $\mathrm{pH}$ reduziu o número de folhas por planta (Figura 1c).

Para altura, diâmetro de caule e matéria seca de raízes, da parte aérea e do total da planta, observouse interação significativa entre $\mathrm{pH}$ versus adubação do solo. Com a elevação do pH, a adubação influenciou negativamente a altura da planta aos 60 e 150DAE (Figura 2a), o diâmetro do caule aos 90, 120 e 150DAE (Figura 2b) e a matéria seca de raízes, da parte aérea e do total da planta aos 150DAE (Figura 2c). A elevação do $\mathrm{pH}$ em conjunto com a presença de adubação, semelhante ao observado para a interação dos fatores pH e horizonte A do solo, resultou em uma redução mais acentuada na matéria seca de parte aérea que de raízes (Figura 2c). A análise do solo realizada aos 150DAE demonstrou redução significativa nos teores de Zn, Fe e Mn, respectivamente em 38\%, 28\% e 89\%, pela elevação do $\mathrm{pH}$ do horizonte A do solo. Já no horizonte $\mathrm{B}$, esse efeito se fez presente apenas nos teores de Zn e Fe, que reduziram em média 36\% e 35\%, respectivamente. Esses dados sugerem que a elevação do $\mathrm{pH}$ do solo utilizado, quando associado ou não a adubação, pode ter causado deficiência desses nutrientes às plantas de grápia.

A influência do $\mathrm{pH}$ do solo sobre o crescimento de espécies florestais apresenta resultados variáveis. Algumas espécies respondem de forma positiva à calagem, como Pinus radiata (HUANG \& BACHELARD, 1993), enquanto que Acacia mangium e Peltophorum dubium tiveram o crescimento radicular não afetado pela condição de solo ácido, sendo que essas duas últimas espécies também responderam melhor à adubação na forma amoniacal que nítrica, sugerindo assim que este comportamento poderia estar associado à adaptação a solos ácidos (DO VALE et al., 1996). A absorção do $\mathrm{N}-\mathrm{NH}_{4}^{+}$pelas raízes, por depender fortemente do gradiente eletroquímico por meio das membranas celulares, estimula a extrusão de $\mathrm{H}^{+}$para a rizosfera (MARSCHNER, 2002). Desse modo, solos ácidos favorecem indiretamente a absorção dessa fonte de N (MARSCHNER, 2002). Quanto à grápia, NICOLOSO et al. (2005) verificaram que a razão de concentração adequada entre as fontes de $\mathrm{N}_{-} \mathrm{NO}_{3}^{-}: \mathrm{N}-$ $\mathrm{NH}_{4}^{+}$na adubação de um Argissolo Vermelho distrófico

Ciência Rural, v.38, n.6, set, 2008. 


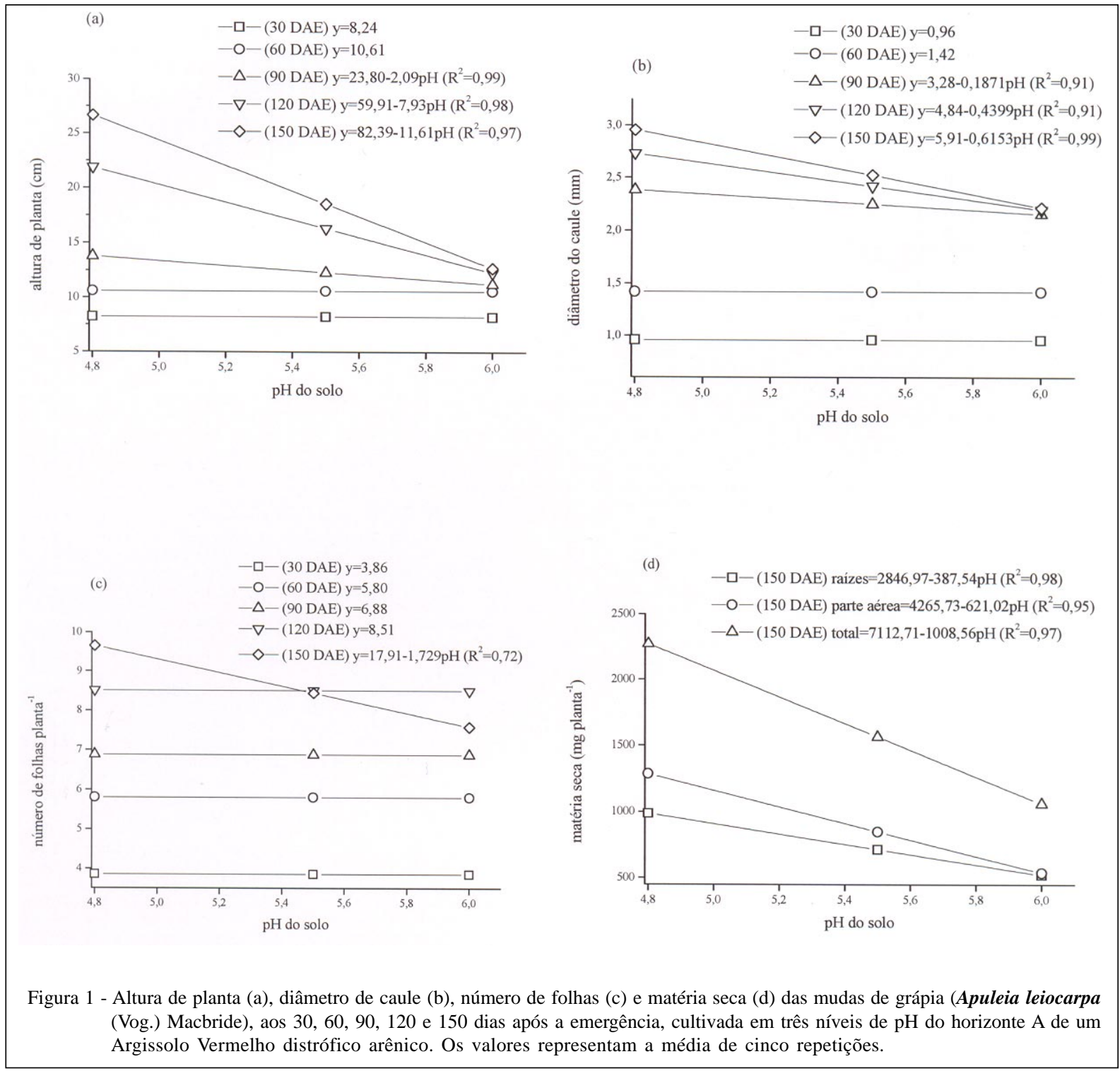

arênico com $\mathrm{pH}$ 4,8 para o cultivo de plantas jovens não deve ultrapassar o valor de 4:1. Isso sugere diferenças marcantes entre as espécies florestais quanto as suas respostas em relação ao $\mathrm{pH}$ do solo e à fonte nitrogenada.

Dependendo da época de avaliação, para altura da planta e número de folhas, verificou-se efeito isolado da adubação e do horizonte do solo. $\mathrm{Na}$ ausência de adubação, a altura da planta não diferiu entre os cultivos realizados nos horizontes A e B do solo, exceto aos 120AE, quando foi menor no horizonte B (Tabela 1). A adubação apresentou efeito significativo na altura de planta somente aos 90 e 150DAE em ambos os horizontes do solo (Tabela 1). Quanto ao número de folhas por planta, na ausência de adubação, houve diferença mais proeminente entre os horizontes do solo, sendo maior no horizonte A aos 30, 60, 90 e 120DAE (Tabela 1). Na presença de adubação aos 120 e 150DAE, o número de folhas também foi maior nas plantas cultivadas no horizonte A que no horizonte B do solo. A presença de adubação, tanto no horizonte A e B do solo, resultou em elevação significativa do número de folhas por planta somente aos 90DAE. Durante todo período experimental, o diâmetro do caule não foi afetado pelo efeito isolado do fator adubação e do fator horizonte do solo (Tabela 1).

O menor crescimento de plantas jovens de grápia no horizonte B de um Argissolo Vermelho distrófico arênico pode estar relacionado com a maior concentração de $\mathrm{Al}^{3+}$ associada à baixa disponibilidade 


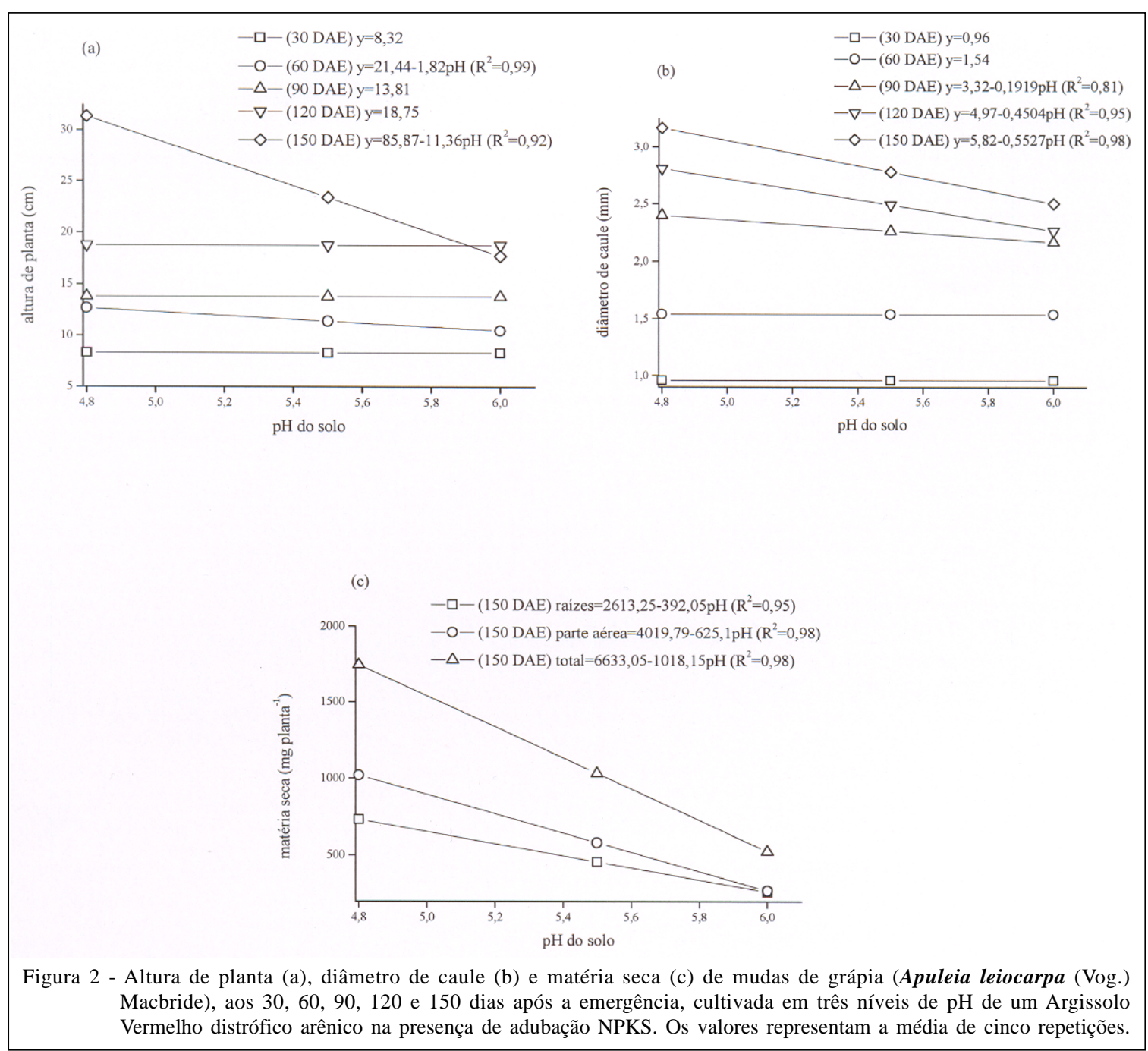

de P neste horizonte, comparativamente ao horizonte A, conforme sugerido por NICOLOSO et al. (1999). Entretanto, FORTUNATO \& NICOLOSO (2004) constataram que plântulas de grápia foram tolerantes ao $\mathrm{Al}^{3+}$ até a dose de $10 \mathrm{mg} \mathrm{L}^{-1}$ em substrato geleificado com agar, fato que dependeu da elevação do $\mathrm{pH}$ da rizosfera pela planta. A elevação do $\mathrm{pH}$ da rizosfera induzida pelo Al em pH ácido tem sido considerada como um mecanismo importante de tolerância de algumas espécies vegetais à acidez elevada, devido ao fato que a toxidez do $\mathrm{H}^{+}$às membranas biológicas ser mais danosa que aquela do $\mathrm{Al}$ (DEGENHARDT et al., 1998).

A matéria seca da parte aérea, variável analisada apenas aos 150DAE, aumentou pela adubação independente do horizonte do solo (Tabela 2). Entretanto, a matéria seca de raízes e o comprimento das raízes foram maiores no horizonte $\mathrm{B}$ independente da adubação (Tabela 2). Esse comportamento sugere uma tentativa de resposta da planta para compensar a baixa disponibilidade de nutrientes, em particular o $\mathrm{P}$, que, quando em condição de deficiência, induz alteração na partição do carbono, a qual proporciona mais carboidratos para o crescimento radicular (MOLLIER \& PELLERIN, 1999), permitindo, assim, um aumento na exploração do solo. Apesar disso, não foi observado efeito significativo do horizonte e da adubação do solo na relação entre a matéria seca de raízes e da parte aérea da grápia, havendo apenas a tendência desta ser maior na ausência de adubação (Tabela 2).

Aos 150DAE, devido à adubação do solo ter aumentado o comprimento das raízes, da matéria seca de raízes, da parte aérea e do total das plantas (Tabela 2), no geral fica demonstrada a baixa fertilidade do solo usado nesse experimento, considerando-se que não houve diferença na matéria seca da parte aérea e do total da planta entre os dois horizontes do solo (Tabela 2).

As espécies florestais podem ser classificadas quanto a aspectos ecológicos, sendo

Ciência Rural, v.38, n.6, set, 2008. 
Tabela 1 - Efeito do horizonte do solo e adubação NPKS na altura de planta, diâmetro de caule e número de folhas de mudas de grápia (Apuleia leiocarpa (Vog.) Macbride), aos 30, 60, 90, 120 e 150 dias após a emergência, cultivada em um solo Argissolo Vermelho distrófico arênico.

\begin{tabular}{|c|c|c|c|c|c|c|c|c|c|c|}
\hline & \multicolumn{2}{|c|}{30} & \multicolumn{2}{|c|}{60} & \multicolumn{2}{|c|}{90} & \multicolumn{2}{|c|}{120} & \multicolumn{2}{|c|}{150} \\
\hline & c/adub. ${ }^{(1)}$ & s/adub. ${ }^{(2)}$ & c/adub. & s/adub. & c/adub. & s/adub. & c/adub. & s/adub. & c/adub. & s/adub. \\
\hline & \multicolumn{10}{|c|}{ 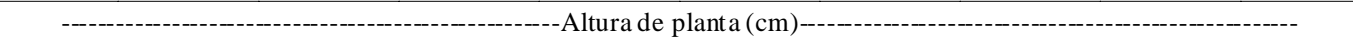 } \\
\hline Horizonte A & 8,4 a $A^{*}$ & 8,5 a $\mathrm{A}$ & 11,9 a $\mathrm{A}$ & 10,1 a $\mathrm{A}$ & 13,9 a $\mathrm{A}$ & 11,2 a B & 19,7 a $\mathrm{A}$ & 13,8 a A & 24,4 a $\mathrm{A}$ & 14,0 a B \\
\hline Horizonte B & 8,2 a $A$ & 7,9 а A & 11,2 a $\mathrm{A}$ & 9,2 a $\mathrm{A}$ & 13,6 a $\mathrm{A}$ & 10,2 a B & 17,7 a $\mathrm{A}$ & 11,6 b A & 23,8 a $\mathrm{A}$ & 12,3 a B \\
\hline \multirow[t]{2}{*}{ CV $(\%)$} & 11,6 & 9,6 & 15,0 & 15,5 & 18,6 & 12,4 & 29,8 & 23,8 & 27,5 & 14,6 \\
\hline & \multicolumn{10}{|c|}{ 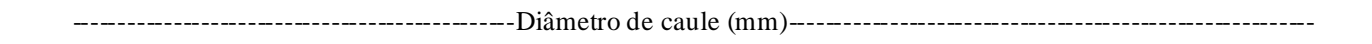 } \\
\hline Horizonte A & 0,99 а $\mathrm{A}$ & 0,99 а $\mathrm{A}$ & 1,58 a A & 1,49 a $\mathrm{A}$ & 2,3 a A & 2,2 a $\mathrm{A}$ & 2,6 a $\mathrm{A}$ & 2,3 a $\mathrm{A}$ & 2,8 a $\mathrm{A}$ & 2,1 a $\mathrm{A}$ \\
\hline Horizonte B & 0,92 а $\mathrm{A}$ & 0,93 а $\mathrm{A}$ & 1,32 a $A$ & 1,28 a $\mathrm{A}$ & 2,2 a A & 2,1 a $A$ & 2,4 a $\mathrm{A}$ & 2,1 a $A$ & 2,8 a $A$ & 2,0 a $A$ \\
\hline CV(\%) & 17,8 & 13,6 & 14,4 & 11,2 & 11,0 & 9,1 & 13,9 & 11,3 & 17,6 & 9,4 \\
\hline \multicolumn{11}{|c|}{ 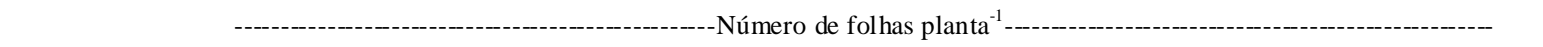 } \\
\hline Horizonte A & 3,8 a A & 3,9 a A & 6,0 a $\mathrm{A}$ & 5,6 a A & 7,5 a $\mathrm{A}$ & 6,3 а B & 9,4 а $\mathrm{A}$ & 7,6 a A & 12,0 a $\mathrm{A}$ & 7,7 a A \\
\hline Horizonte B & 3,7 a $\mathrm{A}$ & 3,4 b A & 5,8 a $\mathrm{A}$ & $5,1 \mathrm{~b} A$ & 7,4 a $\mathrm{A}$ & $5,8 \mathrm{~b}$ B & 8,7 b A & 6,5 b A & $11,3 \mathrm{~b} \mathrm{~A}$ & 7,8 a $\mathrm{A}$ \\
\hline CV(\%) & 9,9 & 12,5 & 10,3 & 9,2 & 11,3 & 11,6 & 17,7 & 25,5 & 198,4 & 15,6 \\
\hline
\end{tabular}

* Médias seguidas pela mesma letra minúscula, na coluna, e maiúscula na linha não diferem entre si pelo teste de Duncan a 5\% de erro.

(1) c/adub.: com adubação NPKS.

(2) s/adub.: sem adubação NPKS.

assim definidos três grupos: pioneiras, secundárias e clímax. CARVALHO (1994) sugere a classificação da grápia como espécie pioneira indiferente à secundária tardia. As espécies pertencentes ao grupo ecológico das pioneiras apresentam maior taxa de crescimento em comparação às espécies clímax (RESENDE et al.,

Tabela 2 - Efeito do horizonte do solo e da adubação NPKS na matéria seca da planta, na relação entre matéria seca de raízes e da parte aérea e no comprimento de raízes de mudas de grápia (Apuleia leiocarpa (Vog.) Macbride) aos 150 dias após a emergência, cultivada em Argissolo Vermelho distrófico arênico.

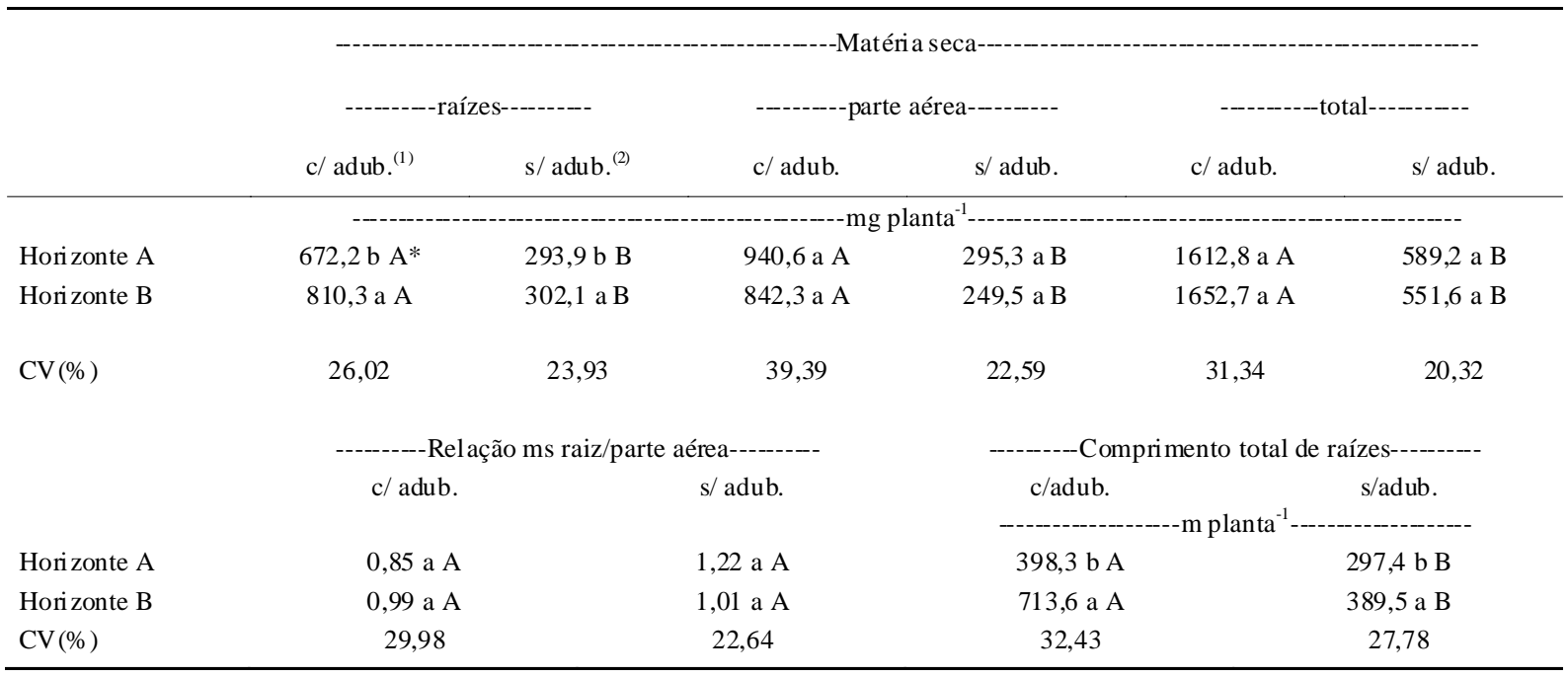

* Médias seguidas pela mesma letra minúscula, na coluna, e maiúscula na linha não diferem entre si pelo teste de Duncan a 5\% de erro.

(1) c/adub.: com adubação NPKS.

(2) s/adub.: sem adubação NPKS. 
1999), de modo que as pioneiras apresentam maior sensibilidade à baixa disponibilidade de nutrientes. Em avaliação de respostas das espécies florestais à condição de acidez, FURTINI NETO et al. (1999a) observaram que aquelas pertencentes ao grupo das pioneiras e secundárias responderam à calagem, ao contrário de espécies clímax. Esse resultado difere do constatado para a grápia, pois no presente trabalho as mudas dessa espécie responderam negativamente à calagem. Entretanto, esse efeito negativo à calagem do solo sobre o crescimento da grápia se deve provavelmente a um distúrbio nutricional, principalmente pela diminuição da concentração de $\mathrm{Mn}$ no horizonte A do solo e, conseqüentemente, na planta. A redução do crescimento das plantas foi acompanhada de sintomas visuais de deficiência desse micronutriente nas folhas mais novas.

Também é importante ressaltar que, nas áreas ocupadas naturalmente pela grápia, os solos predominantes são o Latossolo Vermelho distrófico típico (solo Santo Ângelo), o Chernossolo Argilúvico Férrico típico (solo Ciríaco) e o Neossolo Litólico eutrófico chernossólico (solo Charrua), os quais apresentam distintas características químicas (BRASIL, 1973). O solo Santo Ângelo é muito pobre em fósforo disponível, o pH é em torno de 5,3 e os valores de $\mathrm{Al}^{3+}$ variam de 0,8 a 2,0 $\mathrm{cmol}_{\mathrm{c}} \mathrm{kg}^{-1}$ de solo, bem como apresenta altos teores de Mn. Já os solos Ciríaco e o Charrua, são de ligeiramente ácidos a neutros (pH 5,8 a 6,5) e apresentam alta saturação de bases e com $\mathrm{Al}^{3+}$ praticamente nulo. Portanto, os resultados encontrados em relação ao efeito negativo da calagem, no presente trabalho, devem ser considerados com cautela para os demais solos onde a espécie ocorre.

\section{CONCLUSÕES}

A calagem no horizonte A do Argissolo Vermelho distrófico arênico afetou negativamente o crescimento das plantas jovens de grápia. Recomendase a adubação NPKS para a produção de mudas de grápia somente em condição de $\mathrm{pH}$ moderadamente ácido em Argissolo Vermelho distrófico arênico.

\section{REFERÊNCIAS}

BRASIL. Levantamento de reconhecimento dos solos do Estado do Rio Grande do Sul. Recife: Ministério da Agricultura - Departamento Nacional de Pesquisa Agropecuária - Divisão de Pesquisas Pedológicas, 1973. 431p. (Boletim Técnico, 30).
CARVALHO, P.E.R. Espécies florestais braileiras: Recomendações silviculturais, potencialidades e uso da madeira. Brasília: Embrapa, 1994. 639p.

DEGENHARDT, $J$, et al. Aluminum resistance in the Arabidopsis mutant alv-104 is caused by an aluminum-induced increase in rhizosphere $\mathrm{pH}$. Plant Physiology, Waterbury, v.117, p.19-27, 1998.

DO VALE, F.R. et al. Crescimento radicular de espécies florestais em solo ácido. Pesquisa Agropecuária Brasileira, Brasília, v.31, n.9, p.609-616, 1996.

FORTUNATO, R.P.; NICOLOSO, F.T. Toxidez de alumínio em plântulas de grápia (Apuleia leiocarpa Vog. Macbride). Ciência Rural, Santa Maria, v.34, n.1, p.89-95, 2004.

FURTINI NETO, A.E. et al. Liming effects on growth of native woody species from Brazilian savannah. Pesquisa Agropecuária Brasileira, Brasília, v.34, n.5, p.829-837, 1999a.

FURTINI NETO, A.E. et al. Acidez do solo, crescimento e nutrição mineral de algumas espécies arbóreas, na fase de muda. Cerne, Lavras, v.5, n.2, p.1-12, 1999b.

HUANG, J.; BACHELARD, E.P. Effects of aluminum on growth and cation uptake in seedlings of Eucalyptus mannifera and Pinus radiata. Plant and Soil, Dordrecht, v.149, p.212-127, 1993.

MARSCHNER, H. Mechanisms of adaptation of plants to acid soils. Plant and Soil, Dordrecht, v.134, p.1-20, 1991.

MARSCHNER, H. Mineral nutrition of higher plants. London: Academic, 2002. 889p.

MATTOS, N.F.; GUARANHA, J. Contribuição ao estudo da grápia (Apuleia leiocarpa). Porto Alegre: Instituto de Pesquisas de Recursos Naturais Renováveis "AP”, 1983. 25p. (Boletim Técnico, 12).

MISSIO, E.L. et al. Exigências nutricionais da grápia ao fósforo e enxofre em Argissolo Vermelho distrófico arênico: efeito da adubação no crescimento. Ciência Rural, Santa Maria, v.34, n.4, p.1051-1057, 2004.

MOLLIER, A.; PELLERIN, S. Maize root system growth and development as influenced by phosphorus deficiency. Journal of Experimental Botany, Oxford, v.50, n.333, p.487-497, 1999.

NICOLOSO, F.T. et al. Exigências nutricionais da grápia (Apuleia leiocarpa Vog. Macbride) em solo Podzólico vermelho amarelo. Ciência Rural, Santa Maria, v.29, n.2, p.225-231, 1999.

NICOLOSO, F.T. et al. Recipientes e substratos na produção de mudas de Maytenus ilicifolia e Apuleia leiocarpa. Ciência Rural, Santa Maria, v.30, n.6, p.987-992, 2000. 
NICOLOSO, F.T. et al. Nutrição mineral de mudas de grápia (Apuleia leiocarpa) em Argissolo Vermelho distrófico arênico: efeito da adubação NPK no crescimento. Ciência Rural, Santa Maria, v.31, n.6. p.991-998, 2001.

NICOLOSO, F.T. et al. Fontes de nitrogênio mineral (N-NO e $\mathrm{N}-\mathrm{NH}_{4}^{+}$) no crescimento de plantas jovens de grápia (Apuleia leiocarpa Vog. Macbride). Ciência Florestal, Santa Maria, v.15, n.3, p.221-231, 2005.

REITZ, R. et al. Projeto madeira do Rio Grande do Sul. Porto Alegre: Secretaria da Agricultura e Abastecimento, 1988. 525p.
RESENDE, A.V. et al. Crescimento inicial de espécies florestais de diferentes grupos sucessionais em resposta a doses de fósforo. Pesquisa Agropecuária Brasileira, Brasília, v.34, n.11, p.2071-2081, 1999

TEDESCO, M.J. et al. Análise de solo, plantas e outros materiais. Porto Alegre: Universidade Federal do Rio Grande do Sul, 1995. 174p. (Boletim técnico, 5).

TENNANT, D. A test of a modified line intersect method of estimating root length. Journal of Ecology, Oxford, v.63, p.995-1001, 1975. 